ALEXANDER ANDRASON

University of Stellenbosch

aleksand@hi.is

ADMIRE PHIRI

University of Stellenbosch

phiriadmire1@gmail.com

\title{
THE HĨ AND HA GRAMS IN TJWAO (KHOE) - THE MODEL OF SITUATED MAPS
}

Keywords: TAM, grammaticalization, semantic maps, cognitive linguistics, Khoe-Kwadi

\begin{abstract}
The present paper offers an analysis of the TAM semantics of the HĨ and the HA gram(matical construction)s in Tjwao within the cognitive and grammaticalizationbased model of dynamic maps and streams. The authors show that, albeit similar, the ranges of meanings of the two grams differ. The grams share the senses of experiential present perfect, definite past, stative and non-stative present. However, the senses of narrative remote past and pluperfect are typical of HĨ, while the senses of inclusive and resultative present perfect are only compatible with HA. When used as presents, HA is limited to affirmative contexts, whereas HĨ is restricted to negative contexts. The authors additionally demonstrate that the polysemy of each gram can be mapped by means of two sub-paths of the resultative path, i.e. the anterior and simultaneous paths. The two grams may therefore be located on the same stream on which HĨ occupies a more advanced position than HA, being thus a chronologically earlier construction. This grammaticalization-based entanglement of HI and HA is consistent with the situation found in other Khoe languages
\end{abstract}

\section{Introduction}

The present article contributes to the understanding of the verbal system of a highly endangered and heavily under-researched Khoe language - Tjwao. Specifically, we analyze and compare the $\mathrm{T}($ ense)-A(spect)-M(ood) semantics of two gram(matical 
construction)s that are reported to introduce, indistinguishably, anterior and past events or activities. Given their distinctive markers, i.e. the suffixes - $h \tilde{\imath}$ and - $h a$, the two constructions will henceforth be referred to as the HI and the HA gram, respectively. The study is developed within a cognitive and grammaticalization-based framework of dynamic qualitative maps - or vectors (Croft 2003; Haspelmath 2003; Narrog, Van der Auwera 2011; Janda 2015); and their situated extension - the stream (Andrason 2016a, b; Georgakopoulos, Polis 2018).

Tjwao is a Khoe variety that belongs to the Eastern Kalahari group of the KhoeKwadi branch - one of the five "lineages" of Khoisan (Güldemann 2014: 27; see also Vossen 1997, 1998; Güldemann, Vossen 2000). ${ }^{1}$ The Tjwao language is used by the Tjwa community in the Tsholotsho district of Western Zimbabwe (Hachipola 1998; Phiri 2015). Currently, it is actively spoken by no more than ten elderly persons. Crucially, the language is no longer employed in everyday spontaneous communications, and younger members of the community have, at best, a passive knowledge of it (Phiri 2015). Like the majority of Kalahari Khoe languages, Tjwao is poorly documented, virtually lacking any systematic linguistic description (cf. Güldemann, Vossen 2000: 103; Phiri 2015). ${ }^{2}$

The issue of the TAM semantics of HĨ and HA in Tjwao has not been addressed in scholarly literature. The exact ranges of uses of the two constructions, and their mutual distinctions, are thus far understood poorly - the HĨ and HA grams being both tentatively defined as "past tenses" (Phiri, Wills 2016: 27). The present article aims to rectify this lacuna by offering a more comprehensive analysis of the TAM profile of the HĨ and HA constructions, both at the individual (gram-oriented) and the holistic (system-oriented) level of analysis. Specifically, this study will discern similarities and differences in the meanings conveyed by the two grams, and determine their positions in the Tjwao TAM verbal system.

While the current understanding of the two Tjwao grams is deficient, the differences in meaning exhibited by the cognate forms found in other Khoekhoe or Kalahari Khoe languages - and their systemic positions in the respective linguistic systems - have been analyzed more thoroughly. Such analyses generally suggest that the cognates of HA share similarity with the category of present perfect, while the cognates of HĨ often approximate general or remote past tenses (Hagman 1977; Vossen 1997; Kilian-Hatz 2006; Haacke 2013a, b, 2014; Rapold 2014; Fehn 2016; $\mathrm{Du}$ Plessis 2017). The present paper will verify whether Tjwao conforms to this tendency. ${ }^{3}$

The other lineages are: Hadza, Sandawe, Kx'a, and Tuu (Güldemann 2014: 26-27). Concerning the place of Khoe in the tree of Khoisan languages, its phylogenetic relationship with other languages of the Kalahari Basin, and the internal fragmentation of the entire Khoisan family, consult Vossen (1997, 1998), Güldemann (2014), Güldemann, Vossen (2000), and Güldemann, Fehn (2017).

2 A noticeable exception is a detailed analysis of the Tjwao nominal system developed by Fehn and Phiri (2017).

3 The HA gram is found in all Khoe languages and has been reconstructed for Proto-Khoe (Vossen 1997: 361, 365; Rapold 2014: 169). HĨ, in contrast, is restricted to the Tshwa and Khwe clusters (cf. Kilian-Hatz 2008; Fehn 2016; Rapold 2014). 
To achieve the above-mentioned goals, the article will be structured as follows: In Section 2, we will expound the theoretical framework underlying the research. In Section 3, we will introduce Tjwao evidence illustrating the semantic potential of HĨ (3.1) and HA (3.2). In Section 4, this evidence will be discussed within the adopted framework. Lastly, in Section 5, we will draw the main conclusions of the study, additionally explaining its limitations.

\section{Framework}

We will conduct our study within the model of situated semantic maps. This model has been developed at the intersection of cognitive linguistics and grammaticalization theory. It draws on the idea of dynamic qualitative semantic maps, envisaged as vectors (Croft 2003; Haspelmath 2003; Narrog, Van der Auwera 2011; Janda 2015), and the concept of the so-called stream - a systemic medium of expansion of maps (Andrason 2016a, b; Georgakopoulos, Polis 2018). ${ }^{4}$

The foundation of our model lies in the fact that verbal constructions are inherently polysemous and that this synchronically attested polysemy is coherent. Contrary to traditional, essentialist theories that postulate an invariant abstract meaning present in every component of a polysemous set, we adopt a cognitive approach to polysemy, built around the idea of family resemblance. According to that view, the semantic unity of a form resides in a chain of overlapping similarities exhibited by this polysemy's components. Crucially, even though various pairs of senses exhibited by a form have certain features in common, there need not be a single trait that is pervasive in all the senses, sufficient to define that form both internally (accounting for its role in the language) and externally (in opposition to other forms) (Taylor 2003; Janda 2015; see also Rosch 1975 and Rosch, Mervis 1975). Rather, the cohesion of a polysemous set resides in the cognitively motivated process of meaning extension that, leading from one (similar) sense to another (similar) sense, connects all the components of a polysemous body. This process, which has driven the meaning potential of a form to its current state, coincides with the grammaticalization path (or its part) along which the form has been evolving (Dahl 1985, 2000; Bybee, Perkins, Pagliuca 1994; Bybee 2010). As a result, the various components of the form's polysemy are related historically and conceptually. On the one hand, any given sense has been derived from a predecessor (i.e. a sense attested to at an earlier historical time) and generates a successor (i.e. a sense developed at a later time). On the other hand, the relation between an "older" and a "younger" sense is grounded in human cognitive mechanisms (metonymy, metaphor, context induced reinterpretation, analogy, etc.), which have enabled the extension of the latter from the former (Janda 2015).

\footnotetext{
This model has been developed by Andrason in his work on the verbal system of Mandinka (2016a, b). Subsequently, it has been applied to verbal systems of Hebrew (Andrason 2015), Greek (Andrason, Locatell 2016) and Maasai (Andrason, Karani 2017).
} 
The most efficient representation of these types of polysemous structures is a map. In the map, nodes correspond to senses synchronically available to a construction, while links indicate their historical expansions and conceptual foundations (Croft 2003; Haspelmath 2003; Malchukov 2004). Given that the topology of the map is grounded in grammaticalization phenomena, the synchronic semantics of a form becomes inherently dynamic. Synchrony is metastatic rather than truly static. That is, although we take synchronic objects for inert, they are, in fact, processes. Therefore, synchronic maps can be understood as vectors - a line or network being given direction. Such vectors inform us not only about the semantic potential of a form and ensure its cohesion, but also impose the course of all possible extensions. This involves connections that are currently attested, as well as those that existed earlier (i.e. those that led to the present polysemy) and may exist later (i.e. those that are likely to emerge at posterior evolutionary stages; cf. Andrason 2016a).

The vector model depicts a gram in isolation from the other components of the language system. Certainly, no grammatical element "floats" in a grammatical vacuum. Synchronically, the polysemous form exists in the context of other polysemous forms. Diachronically, the polysemy has emerged not only due to the meaning of the input construction (i.e. the lexical source), but has also developed in response to the constantly changing properties of the linguistic environment, in particular, other constructions found in the same section or layer of the grammar. By using the concept of a grammaticalization path in a more abstract, more idealized, more general, and more coarse-grained manner, a vectored map can be situated in its adjacent environment or a medium of expansion. This environment is referred to as a stream (Andrason 2016a, b). In contrast to vectors, which refer to specific grammatical developments, the stream makes reference to a generalized, non-concrete evolutionary pattern that has recursively been activated in a language. Therefore, it can accommodate vectors - and, thus, grammatical evolutions - which, at more fine-grained approximation, are (slightly) dissimilar, having emerged from different sources and at different times.

By locating a vectored map on the stream, that map becomes a map in context. It is preceded and followed by other maps or vectors. The preceding vectors emerged earlier - they constitute older grammatical phenomena. In contrast, the vectors that follow are posterior - they are younger phenomena. This means that any vectored map exists in an inseparable entanglement with other maps. For a stream that is populated by two vectored maps, the older vector escapes from the younger, while the younger vector chasses the older. As a result, the systemic role of a gram does not only depend on the internal properties of that gram, even though these remain crucial since they deliver a vectored-map representation. The status of a form in a language system is also conditioned by the position of the vectored map in relation to the other maps on the stream (Andrason 2016a, b).

Overall, the concept of a stream bestows us with a dynamic manner of modularizing a given language system: We divide the language into modules that have emerged due to the action of similar evolutionary forces. In this manner, sub-parts of a language system - like vectors representing the grams - become dynamic instead 
of being static. In other words, instead of dividing the grammar into a tense system, an aspectual system, a present-time system, a past-time system, etc., we can modularize it into dynamic units, on which various TAM senses and constructions co-exist (Andrason 2016a, b; for a comprehensive overview and compelling discussion of the various types of semantic maps, consult Georgakopoulos, Polis 2018).

To conclude, the dynamic approach to a TAM system presented above necessitates the following three methodological steps: (1) the description of the semantic potential of a form; (2) the development of a grammaticalization-based semantic map of that form; and (3) the positioning of the map on the stream in relation to the other maps. The subsequent parts of this paper will be devoted to execute this research plan.

\section{Evidence}

The present section introduces original evidence related to the polysemy of the HI and HA grams. This evidence was collected during fieldwork activities that were carried out in Tsholotsho (Zimbabwe) in 2015, 2016, and 2017. ${ }^{5}$ Ten native speakers of Tjwao participated in the study, which formed part of a wider research project. The principal objective of that research was to document and describe the verbal system of Tjwao.

As mentioned in Section 1, the HĨ and HA grams are formed by suffixing the morphemes - $h \tilde{i}$ and $-h a$, respectively. However, these suffixes are not attached directly to the verbal stem. They require a grammatical element that in literature has been referred to as a "juncture morpheme" or a "verbal linker" (Köhler 1981; Elderkin 1986; Heine 1986; Vossen 1997, 2010; Kilian-Hatz 2006; Güldemann, Fehn 2014; Rapold 2014; Fehn 2016). In Tjwao, the juncture exhibits five allomorphs: -a-, -na-, $-r a-,-r e-$, or $-r o .{ }^{6}$ In negative constructions, the juncture is absent.

\subsection{The HĨ gram}

The HĨ gram conveys the meaning typically associated with an experiential present perfect. Accordingly, it communicates that the subject has the experience of performing an activity or an action. The action itself might have occurred a long time ago and its results may no longer be palpable - crucially, the reality may have changed since the moment where the expressed event occurred. However, the action remains relevant as it constitutes part of the permanent experience of the subject. The nuance of current relevance is also evident in that the experienced event cannot be accompanied by an

\footnotetext{
The transcriptions of the examples collected during the 2015 fieldwork have been developed by Anne-Maria Fehn. Some of the examples elicited from native speakers were inspired by similar sentences from Dornan (1917) and Phiri, Wills (2016). The examples provided in this section have been corroborated by native speakers in course of the fieldwork that was conducted by A. Phiri in Tsholotsho in 2017.

6 Such junctures occur in all Kalahari Khoe varieties and, as in Tjwao, exhibit several allomorphs (Vossen 1997, 2010).
} 
expression (e.g. an adverb or adverbial clause) that would locate it in a specific moment in the past. Rather, adverbials of a general and inclusive scope - i.e. those that extends over the present reference time - are used (see for instance the lexeme xoyo. $? e$ 'ever' in 1.a-b below). As further illustrated by these two examples, the experience communicated by the HĨ gram may be positive (1.a) or negative (1.b):
(1) a. Tca xoyo.Re ndjuu Ilan-a-hĩ Re?
2.SG.M ever house build-J-HĨ Q
'Have you ever built a house?'
b. Ti xoyo.?e k'ao.tco l'ũũ-tam-hĩ
1.SG ever man kill-NEG-HĨ
'I have never killed a man'

The HĨ gram may be used in the function of a definite past tense. In such cases, its temporal reference is specified by means of adverbials (adverbs, prepositional phrases, nouns used adverbially, etc.), subordinate clauses, or general context (e.g. 3uu.pakela 'this morning' in 2.b, and Pui.ka 'yesterday' in 2.c). When functioning as a past tense, the HĨ gram may introduce events of any temporal distance from the speaker's or narrator's present. To begin with, past events may be temporally proximate, for instance: immediate (2.a), hodiernal (2.b), and hesternal (2.c):

(2) a. Tshaa Re.ce djira-na-hĩ

water 3.SG.F ask-J-HĨ

'She (just) asked for water'

b. Tcoa.na lam tsua=re l'ũũ-a-hĩ ?uu.pakela ${ }^{8}$

1.PL.C two elephants=PL kill-J-HĨ this.morning

'We shot two elephants [...] this morning'

c. Tire maa Pui.ka k'ui-a-hĩ

1.SG mother yesterday talk-J-HĨ

'Yesterday I talked to the mother'

The events expressed by the HĨ gram may also be distant, having occurred a few days ago (3.a), a few months ago (3.b), or a long time ago (3.c). As a result, the gram is often used in personal life narratives (one's life story) and in historical accounts (folk tales, legends, tribe's history etc.; see again 3.c, which forms part of a larger narrative section).

In all the examples, the relevant forms of the HĨ and HA gram will be marked in bold. In this paper, the tone will not be indicated because the analysis of the tonal system of Tjwao remains in its preliminary phase (cf. Phiri 2015). In our examples, we use the standard Tjwao orthography, following Fehn (2016). The most significant convention that departs from the IPA alphabet concerns the graphemes $\langle\mathrm{c}\rangle$ and $\langle\mathrm{t} \mathrm{c}\rangle$, which represent the sounds [ $\mathrm{f}]$ and [ $\mathrm{t}\}]$ respectively. In loanwords, however, the original spelling $s h[S]$ is preserved.

8 The lexeme pakela is not originally Tjwao. It is a Kalanga word. 
(3) a. Tsua yii dzini nua ?e I|2oo-hĩ elephant some day ago COP die:J-HĨ 'The elephant died a few days ago'

b. Wuu ngee-ta nlloe tire kwelo ?o kũũ-tam-hĩ, DEM pass-NEG.IPFV month 1.SG school LOC go-NEG- HĨ ti kua ka tcii 1.SG IPFV ANT be.sick

'Last month (lit. past month), I did not go to school because I was sick'

c. Tire ti nuu xuu-a aa-hĩ Tcolotco wa

1.SG 1.SG land leave-J come:J-HĨ Tcolotco LOC

ti kua Tjwao k'ui

1.SG IPFV Tjwao speak

'Since I left my land and came to Tsholotsho, I speak Tjwao'

As is already evident from the examples introduced thus far (see especially 2.b and 3.a), the HĨ gram can be used in a perfective past sense. In such cases, it expresses actions that are punctiliar, complete, and temporarily bounded. Two further examples illustrating this usage are provided below:

(4) a. Pui.ka ti mamare \|loo-hĩ yesterday 1.SG grandmother die:J-HĨ 'My grandmother died yesterday'

b. ?uu Pe.tsara tolo kũũ-a-hĩ

morning 3.DU.M store go-J-HĨ

'In the morning, we went to the shop'

However, the actions and activities expressed by the HI gram may also be durative, spanning larger periods of time, for instance: hours (5.a), days (5.b), months, and even years (5.c). In these types of examples, the gram exhibits a non-perfective aspectual value.

(5) a. Pui.ka tire buthanu nako shinga-na-hĩ yesterday 1.SG five time work-J-HĨ

'Yesterday I worked for five hours'

b. ?ui.ka tire dzini ?iye shinga-na-hĩ yesterday 1.SG day all work-J-HĨ

'Yesterday I worked all day'

c. Yii nyũũ-?o ?a tire lam.gume kore=ra nyũũ-a-hĩ

DEM stay-LOC OBL $1 . S G$ twenty year=PL stay-J-HĨ

'I lived here (= in this place) for twenty years'9

The HI gram may also be used in the function of a pluperfect. Accordingly, it denotes a past event that chronologically preceded other past events (6.a); or it introduces a past event from a mental space that is already located in the past (6.b):

\footnotetext{
9 At that moment, the speaker no longer lived there.
} 
(6) a. Pui.ka Re.tsara tolo kũũ-a-hĩ ?e.be \|xao IPuru-a-hĩ yesterday 3.DU.M store go-J-HĨ 3.SG.M spear forget-J-HĨ 'Yesterday they went to the shop because he had forgotten the spear'

b. Pui.ka Re.beti.a boori-na-ha ngee-ta dzini ?e.m hĩi-a-hĩ yesterday 3.SG.M 1.SG tell-J-HA pass-NEG.IPFV day 3.SG.M do-J-HĨ 'Yesterday he told me that he had already done it a day earlier (lit. past day)'

The sense of anteriority associated with the categories of present perfect (1) and pluperfect $(6 . a-b)$ is also visible in a future time frame. In such cases, the HĨ gram functions as a type of a future perfect. This usage is confined to a few subordinate contexts, and involves only negative forms of the HĨ gram.

(7) Tcoa.na Tcolotco kũũ-tam-hĩ tsi.tco kua ndjaa

1.PL.C PN go-NEG-HĨ 1.PL.C IPFV dance

'Before we go to Tsholotsho, we dance'

When stative roots are inflected in the negative form of the HĨ gram, they usually express negative present states or qualities - either permanent (8.a) or temporary (8.b) - that characterize the subject. With some verbs (e.g. verbs related to cognition and perception, and verbs of residing), the present-time reading does not concern a state or quality of the subject, but rather denotes an activity - be it currently ongoing or generally possible (8.c).

(8) a. Tire tsxãã-tam-hĩ.

1.SG be.tired-NEG-HĨ

'I am not tired'

b. Yii gee tsao-tam-hĩ

DEM cow be.fat-NEG-HĨ

'This cow is not fat'

c. Tire Re.ba Tana-tam-hĩ

1.SG 3.SG.M know-NEG-HA

'I don't know him'

However, the same forms may also refer to a past time frame, thus conforming to the reference time of the majority uses of the HĨ gram discussed in this section:

(9) a. Pui.ka tire tsxãã-tam-hĩ

yesterday 1.SG tired-NEG-HĨ

'I did not feel tired yesterday'

b. Wuu ngee-ta nlloe tire llaba-tam-hĩ

DEM.REF pass-NEG.IPFV month 1.SG hungry-NEG-HĨ

'Last month (lit. past month), I did not feel hungry'

The past reading is obligatory if stative verbs appear in the positive form of the HĨ gram (10). In such cases, the interpretation is invariably dynamic - to be exact, inchoative, translatable as 'getting into a state': 

(10) Pui.ka tire shubu tsxãã-hĩ yesterday 1.SG suddenly tired:J-HĨ 'Yesterday I suddenly got tired'

\subsection{The HA gram}

The HA gram is used in various functions characteristic of the category of a present perfect. To begin with, it may convey the sense of a resultative present perfect. In such instances, the gram expresses a dynamic anterior action whose effects persist since the moment of its occurrence. For example, in (11.a), the person, a woman, has gone to the village and remains there - she has not returned yet. In (11.b), the male subject still has no recollection of a certain matter.
(11) a. Re.be Rae. ?o kũũ-a-ha
3.SG.M village.LOC go-J-HA
'He has gone to the village'
b. Re.be I?uru-a-ha
3.SG.M forget-J-HA
'He has forgotten'

In the resultative perfect uses discussed above, the HA gram communicates the idea of current relevance - the event is relevant for the present state of affairs because its results are still palpable. The nuance of current relevance is similarly visible in (12). Here, the informant communicates that the chief's wife has handed out water and no longer has it:
(12) \|Pae.xa gllae.tco tshaa maa-ha
chief wife water give:J-HA
'The chief's wife has handed out water'

The HA gram may also be used in the sense of an experiential present perfect. As explained in section 3.1, in such cases, it is not the results of an action that remain unchanged and hence relevant. It is rather the general experience of having performed an action - or not - that is significant for the subject and his/her current state and/or cognitive reality:

(13) Tire k'oo.xo 2yũũ-a-ha

1.SG meat eat-J-HA

'I have eaten meat (in general in my life)'

Moreover, the HA gram may function as an inclusive present perfect. Accordingly, the construction introduces an activity that has been occurring since a certain moment in the past till the present.

10 As will be explained in Section 3.2, to express an affirmative stative sense, the HA gram must be used. 
(14) Tuu ?e nona ?e |am=re tuu-a-ha rain 3.SG.C three COP day=PL rain-J-HA

'It has been raining for three days (lit. It is rain, it is for three days, it has been raining)'

The HA gram allows for a variety of definite-past uses. To begin with, it is employed in the function of an immediate past, communicating actions or activities that (have) occurred just now. For example, in (15.a), hearing a noise from the cooking place, the speaker enquires, perplexed, about its origin. Analogously in (15.b), the speaker asks about an event that must have occurred a few seconds earlier.

(15) a. Tca nao hĩi-a-ha?

2.SG.M what do:J-HA

'What did you do?'

b. Nlee nao hĩ̃-a-ha?

now what do:J-HA

'What just happened?'

A similar immediate-past sense is found in (16). In this example, the female speaker asks her male interlocutor, right after he woke up, about the quality of his sleep:

(16) Tca kãĩ-se lloe-ha ?e?

2.SG.M good-ADV sleep:J-HA Q

'Did you sleep well?'

Being compatible with a near-past time frame, the HA gram may express events that took place earlier the same day (hodiernal past; 17.a-b) and yesterday (hesternal past; $17 . c)$ :

(17) a. Dube ?e.be tsũĩ ndjuu ?uu llan-a-ha

PN 3.SG.M small house morning build-J-HA

'Dube built a small house this morning'

b. Hii-tshee k'aro-are Re.tsara djii.dum ?o lRee papa-na-ha

DEM-day boy-PL 3.DU.M forest LOC fire kindle-J-HA

'The boys set fire to the forest today'

c. Pui.ka tire tca mũũ-a-ha

yesterday $1 . S$ S 2.SG.M see-J-HA

'I saw you yesterday'

The HA gram may also express past events that are more distant from the speaker's present reference time. In such instances, it functions as a general past tense (18). However, the HA gram does not usually introduce remote events, especially those found in (oral) narratives.

(18) Gllae.tco \|1oo-ha nglloe ka

woman die:J-HA month OBL

'The woman died last month' 
As can be observed in examples (17.a-b), (18) and (19), the HA gram expresses past actions that are punctiliar, complete, and bounded, thus exhibiting a canonical perfective aspectual value. Similarly, in the following example, the HA gram introduces a perfective past event of the death of an elephant - the event was complete, happened at once, and can be imagined as a point on the time line:

(19) Tsua IlPoo-ha

elephant die:J-HA

'The elephant died'

Nevertheless, non-perfective past actions - especially those that are not punctiliar, but span larger periods of time - may also be expressed by the HA gram. In such instances, the construction approximates the category of a durative past:

(20) a. $2000 \mathrm{ka}$ tire kae.tca-na-ha gume nglloe-ra 2000 OBL 1.SG hunt-J-HA hunt month-PL

'In 2000, I hunted for months'

b. June tire kae.tca-na-ha December kua.za.sii

June 1.SG hunt-J-HA December until ${ }^{11}$

'I hunted from June to December'

Additionally, the HA gram can be used to convey the value of a pluperfect as illustrated in (21), where it introduces an event that occurred before another action located in a past time frame. However, in most cases, the informants preferred the HĨ gram in such "pluperfectal" contexts, which may be related to a remote-past interpretation of the majority of such examples (compare with 6.a-b in Section 3.1):

(21) Tire maa k'ui-a-hĩ lũã=re windi=ra l'ũũ-a-ha

1.SG mother talk-J-HĨ child=PL window=PL kill-J-HA

'I talked to the woman (whose) children had broken ('killed') the windows'

While with dynamic roots, the HA gram tends to express anterior (perfectal) or past senses, with stative (adjectival) roots, its default reading is present - in particular, a present state. Accordingly, the gram expresses qualities of the subject that can be either transitory or permanent, for instance being tired (22.a), broken/dead (22.b), or fat (22.c). Other roots that yield a present stative meaning in the HA form are Ilxoo 'dry out' (IIxoo-ha 'is dry'), l'oe 'fill up' (l'oe-ha 'is full'), and nllao 'grow old' (nllao-ha' is old'), etc.

(22) a. Tire tsxãã-ha

1.SG tired:J-HA

'I am tired'

b. Mota k'ao.tco de II?oo-ha

car man POSS die:J-HA

'The man's car is broken (lit. is dead)'

11 Kuazasii (or written separately as kua za sii) is a complex locution composed of the imperfective morpheme kua and the verb sii 'arrive'. 
c. Yii gee tsao-a-ha

DEM cow fat-J-HA

'This cow is fat'

Additionally, with a few roots related to the idea of cognition, perception, and residing, the present interpretation of the HA gram has no stative undertones. Instead of expressing qualities of the subject, the gram rather communicates a present activity, be it currently ongoing (23.a), permanent (23.b), or a-temporal and potential (23.c). In such cases, the gram corresponds to the category of a non-stative simple present.

(23) a. Tire Re.ba Pana-ha

1.SG 3.SG.M know:J-HA

'I know him'

b. Na.maa tca nyũũ-a-ha?

where 2.SG.M reside-J-HA

'Where do you live?'

c. Tswana=re djuu llan Pana-ha

Tswana $=\mathrm{PL}$ house build know:J-HA

'The Tswana know how to build a house'

If, however, the temporal reference is located in the past, the same construction - i.e. the HA gram derived from stative roots and roots such as ?ana 'know' or llan 'live' conveys the sense of a stative past (24.a) or a simple past (24.b):

(24) a. Pui.ka tire Ilaba-ha

yesterday 1.SG hungry:J-HA

'Yesterday I was hungry'

b. xa xo tire ?ana-ha

DEM thing 1.SG know:J-HA

'I knew it'

In order to introduce a past stative reading more explicitly, one may use the morpheme of anteriority $k a$ (25.a). The presence of the element $k a$, together with the imperfective marker kua becomes obligatory if the sense of a negative past stative is to be expressed (25.b-c)

(25) a. Pui.ka tire ka llaba-ha

yesterday 1.SG ANT hungry:J-HA

'Yesterday I was hungry'

b. Pui.ka tire ka kua llaba-ha tam yesterday 1.SG ANT IPFV hungry:J-HA NEG

'Yesterday I was not hungry'

c. Pui.ka tire ka kua tsxãã-ha tam yesterday 1.SG ANT IPFV tired:J-HA NEG

'Yesterday I was not tired' 


\section{Discussion}

\subsection{Results}

The evidence provided in Section 3 indicates that even though similar, the ranges of meanings exhibited by the HĨ and HA grams are not identical. Moreover, although largely compatible with the function of a definite past, the two constructions serve many other semantic purposes - they are not only past tenses.

The HI gram is principally used in definite past functions - both perfective and durative, and with any degree of temporal distance - as well as in the sense of a pluperfect. To a significantly lesser extent, the construction expresses senses of a present perfect and a (stative or non-stative) present. As for the perfectal senses, the HĨ gram is compatible only with an experiential sub-type of present perfects. With respect to present senses, these are tolerated by a set of stative roots and verbs of cognition, perception, and residing, being additionally constrained to negative contexts. Lastly, a future-perfect usage is extremely sporadic.

The HA gram is extensively used as a present perfect, being compatible with all its subtypes: inclusive, resultative, and experiential. It also functions as a definite past - both perfective and durative - especially, if the expressed events are located in a less distant time frame. In contrast, temporarily remote events found in (oral) narratives are usually not expressed by the HA gram - it is rather the HI gram that is used in such instances. Furthermore, the HA gram can convey the senses of present stative and general present. This usage concerns stative roots and verbs of cognition, perception, and residing, and is only found in affirmative contexts. In exceptional cases, the HA gram is employed in the function of a pluperfect.

\subsection{Maps}

The results of our study summarized above indicate that, although the semantic differences between the HĨ gram and the HA gram are unmistakable, the two constructions cannot be identified with distinct, discrete and, to an extent, opposite labels. For example, the HĨ gram cannot be defined as a past and the HA gram as a perfect. Nor can the HĨ and the HA grams be analyzed as a near past and a remote past, respectively. As demonstrated in Section 3, the HĨ and HA grams are characterized by a wide and diverse array of semantic domains; and for many of them, the two constructions constitute alternative options. Simply put, their polysemous sets are complex and they intersect. This renders the essentialist hypothesis - built around the idea of an invariant basic meaning and binary oppositions - unsatisfactory. A more suitable manner of defining the HĨ and HA grams is offered by the model of semantic maps, whose tenets have been outlined in Section 2.

Having determined the range of polysemy of the HĨ and HA grams, we will proceed to the next step in the construction of the dynamic TAM model. Specifically, as required by the adopted method, we will organize the respective sets of senses exhibited by the HĨ and HA constructions into coherent maps that coincide with typologically pervasive grammaticalization paths. Inversely, grammaticalization 
tendencies observed across languages will be used as templates for structuring the semantic potential of the studied forms in Tjwao.

The ranges of meanings exhibited by the HĨ and HA grams - namely, present perfect, definite past, perfective and non-perfective (durative) past, pluperfect, future perfect, stative present, and non-stative present - coincide with stages of the so-called resultative path (Andrason 2014, 2016a). This evolutionary path is one of the most pervasive grammaticalization tendencies (Bybee, Perkins, Pagliuca 1994) and consists itself of two sub-paths: the anterior path and the simultaneous path.

The anterior path schematizes a grammaticalization process during which resultative proper inputs gradually acquire the ability of functioning as present perfects and, subsequently, as definite past tenses. The incorporation of the various values typical of a present perfect occurs in the following order: inclusive $>$ resultative $>$ experiential (Andrason 2014, 2016a). Similarly, the development into a general definite past, may be gradual, as the gram becomes compatible with increasingly more distant time frames. That is, it is first used to introduce non-distant past events or activities (immediate $>$ hodiernal $>$ hesternal $>$ recent) and later, more distant ones (general > remote; cf. Bybee, Perkins, Pagliuca 1994). In certain languages, the development into a broad definite past is related to an aspectual change (from a perfective past to a non-perfective past) and with a change involving genre (discourse/oral > written/narrative; for a detailed description of the anterior path consult Nedjalkov, Jaxontov 1988: 3-63; Bybee, Perkins, Pagliuca 1994: 55-57, 98, 104-105; Dahl 2000: 15; Squartini, Bertinetto 2000: 406-417, 422; Nedjalkov 2001: 928-940; Heine, Kuteva 2006: 150-152; Andrason 2014, 2016a). The anterior path outlined above concerns resultative inputs that originate in a present time frame. However, resultative constructions may sometimes be used within a past and a future time frame. In such cases, they acquire the values of a past perfect (pluperfect) and a future perfect, respectively (see Andrason 2011, 2014, 2016a).

Resultative proper inputs - and thus forms that develop towards perfects and pasts - may also evolve in an opposite direction, i.e. towards present tenses. This development is referred to as the simultaneous path (Andrason 2014). During this evolution, resultative proper presents acquire the senses of stative presents and, subsequently, non-stative presents. At the end, they may function as fully-fledged presents, as demonstrated by Preterite-Present verbs in Germanic languages (Maslov 1988: 70-71; Bybee, Perkins, Pagliuca 1994: 74-78; Drinka 1998: 120; Andrason 2014, 2016a). The operativeness of this path is lower than is the case of the anterior path. The simultaneous path typically involves stative verbs as well as verbs that naturally lend themselves for stative inferences (e.g. perception, sensory, and cognition verbs, as well as verbs of residing, getting, or having). Moreover, since the anterior path constitutes a more robust evolutionary tendency, it gradually attracts all the verbs that can participate in (i.e. derive) the evolving gram, including those that are stative (Andrason 2014, 2016a).

By using the complex template of a resultative path, the semantics of the HĨ and HA grams can be defined, structured, and comprehended. This can be achieved without tracing the actual semantic development of the two constructions. We assume 
that the synchronic polysemy has arisen due to the most likely evolutionary scenario - in this case, the resultative path. In other words, the map is derived not from a grammaticalization process observed across time, but is rather founded on its currently observable results (i.e. both forms' polysemy) and their compatibility with crosslinguistic evolutionary tendencies. This method is granted by the pervasiveness of certain developments across languages and cognitive processes that enable them the senses of a gram can be organized into a coherent map because certain types of polysemy tend to be acquired in a well-determined and unidirectional manner (Heine, Claudi, Hünnemeyer 1991; Heine 1997; Haspelmath 2003). ${ }^{12}$

As far as the HĨ gram is concerned, the anterior path enables us to structure the residual senses of present perfect, as well as the values of perfective past and non-perfective (durative) past exhibited by this construction. It also accounts for pluperfect and future-perfect uses, treating them as manifestations of the same path, merely located in the other time frames. In contrast, the simultaneous path makes it possible to account for the value of a negative present - stative and non-stative. As is regular crosslinguistically, this path operates only in the set of stative and cognitive-perceptual roots, as well as verbs of residing. However, the positive variants of verbs that yield negative present senses (either stative or non-stative) adhere to the anterior path rather than the simultaneous path, as they regularly exhibit inchoative, perfectal or past, values.

A coarse-grained map of the HĨ gram is represented in Figure (1.a). A more finegrained depiction of the part of the map organized along the anterior path - where different variants of the present-perfect domain and different types of the past are distinguished - is presented in Figure (1.b).

The same pair of paths enables us to organize the semantic potential of the HA gram, be it at a coarse-grained (Figure 2.a) or fine-grained (Figure 2.b) level of analysis. The anterior path accounts for all the variants of the present perfect, and for the definite past values, among which the remote past is highly exceptional, being absent in narratives. In contrast, the simultaneous path - which, as is typical across languages, is travelled by stative verbs and verbs of cognition, perception, or residing - links the perfectal and past uses to the senses of a stative present and a non-stative present. ${ }^{13}$

12 This method is commonly used in instances where a language lacks direct diachronic data that could show how the polysemy of a form has actually arisen. Tjwao is a language whose development cannot be traced in texts across centuries. There are no direct diachronic data that would attest how the polysemous sets exhibited by the HĨ and HA grams have been acquired. As a result, the hypothesized maps of the two constructions and their positions on the stream cannot be directly verified. They may only be postulated in light of the synchronic evidence and typological regularities.

13 As mentioned above, we do not have direct data (texts) that could corroborate the maps. The origin of the HĨ and the HA grams has only been reconstructed by means of a comparative method. According to most scholars, the two forms - as constructions - developed from bi-verbal compounds linked by an element that nowadays functions as a juncture (Du Plessis 2017: 141). This means that the element that currently surfaces as a suffix (e.g. - hi and -ha in Tjwao) was originally a fully-fledged verb. There is a widespread agreement that the characteristic suffix of the HA gram and its cognates derive from the verb $h \tilde{a}(\tilde{a})$ 'be (there/located), 

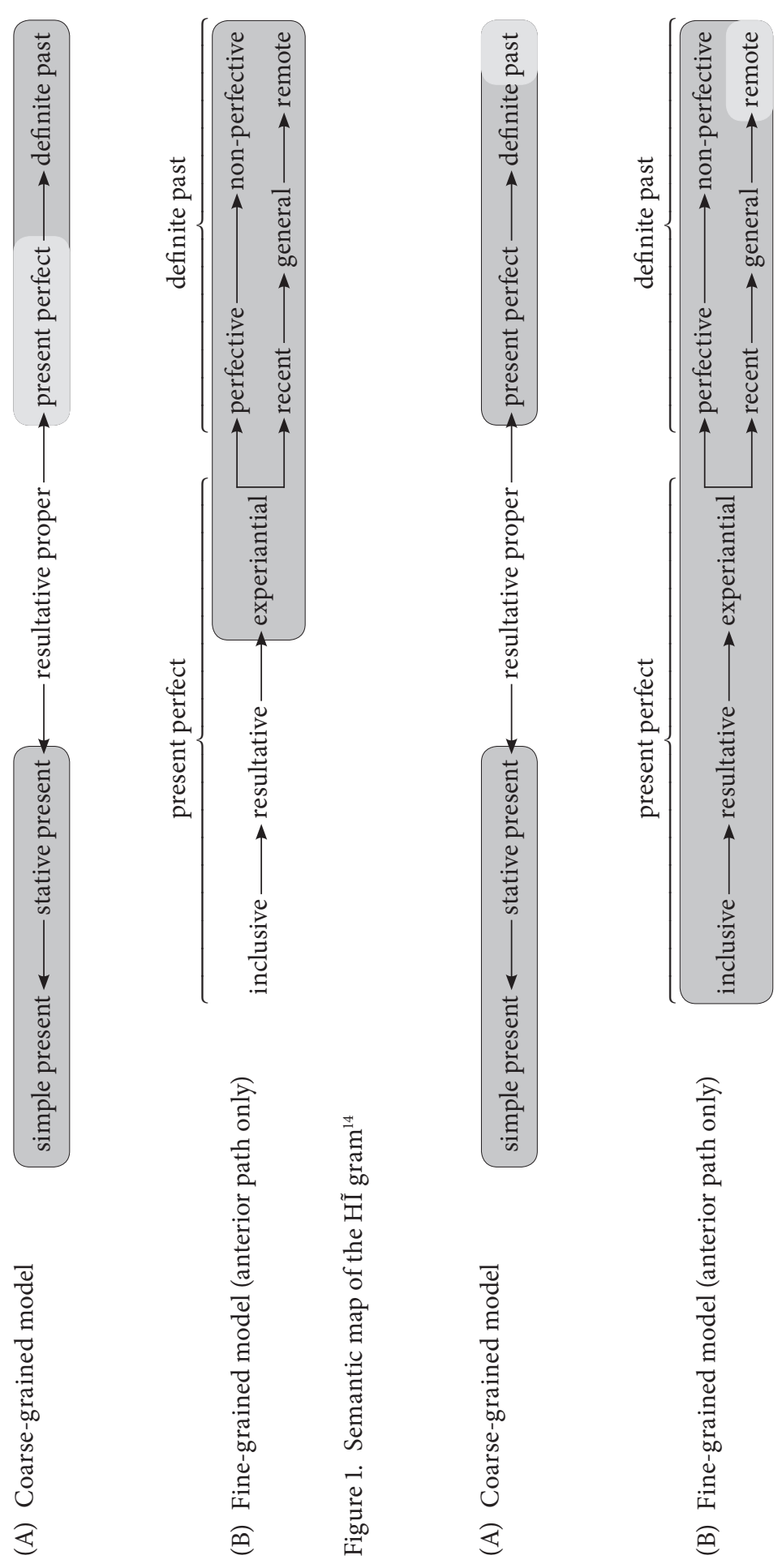

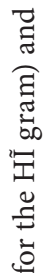




\subsection{Stream}

The maps posited in the previous section enable us to define the HI and HA grams, preserving their internal diversity and coherence. On the one hand, the definitions account for all the senses expressed by the grams. On the other hand, they impose a logical structure of each polysemy - they establish a network of relationships that ties that polysemy's components. In this section we will demonstrate that the concept of stream makes it possible to explain the definitional similarity and dissimilarity of the two constructions, and - even more importantly - to determine their positions in the Tjwao verbal system.

Given that the semantics of the HĨ and the HA gram are organized according to the same evolutionary template, the resultative path - specifically, its two subpaths, the anterior and the simultaneous path (see Sections 4.1 and 4.2 above) - both constructions must have undergone the same type of evolution. By using the concept of a stream, we can locate the two grams on a shared developmental channel that matches the aforementioned stages of the resultative path. Consequently, the maps of the HĨ and the HA gram are no longer disconnected from each other and depicted as if in a grammatical vacuum. On the contrary, they become situated in the context of their respective predecessor or successor.

Between the two constructions that populate the resultative stream in Tjwao, it is the HĨ gram that exhibits a more advanced profile, while the HA gram is topologically less advanced. Specifically, the HĨ form spans over the more advanced parts of the anterior path, such as the last stage of a present perfect and the definite past, including its remote, narrative type. In contrast, the HA form covers the more initial segments of the anterior path: present perfect (especially its less advanced variants) and near or general definite past. Crucially, the use of the HA construction when narrating remote past events is exceptional - this usage being typical of the HI form. Similarly, the HĨ gram may be viewed as more advanced on the simultaneous stream than the HA gram. Although both constructions are compatible with present senses (stative and non-stative), the HĨ gram is used in negative contexts, while the HA gram appears in affirmative contexts. This is consistent with a dynamic typology of resultative-path grams, whereby more advanced resultative-path grams are sometimes limited to negative uses, while less advanced resultative-path grams are first generalized in affirmative contexts. ${ }^{14}$ Moreover, as is typical of more advanced resultative-path grams, the anterior path exerts a dominant role in the HI construction, gradually attracting roots that, at least initially, might have travelled

exist, abide' (Vossen 1997: 361, 365; Kilian-Hatz 2006: 102; Fehn 2016: 147; Du Plessis 2017: 141), which may still be found in the majority of Khoe languages (Vossen 1997; Rapold 2014: 169). As for the origin of the HĨ gram, two views coexist in scholarship. According to the prevalent opinion, the suffix - hĩ derives from the verb $h \tilde{i}(\tilde{\imath})$ 'to make, to do' (Kilian-Hatz 2006: 104; see

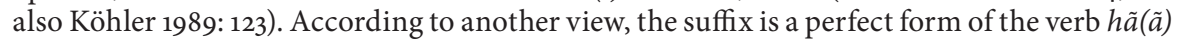
'be (there/located), exist, abide' (Hagman 1977: 83, 93; Du Plessis 2017: 144).

14 See for example, the entanglement exhibited by the old preterite yaqtul in Arabic and Akkadian and the younger grams kataba and iptarras, respectively (Andrason 2013). Concerning different types of specialization towards positive and negative contexts exhibited by two successive resultative-path grams, consult Andrason (2016a, b). 


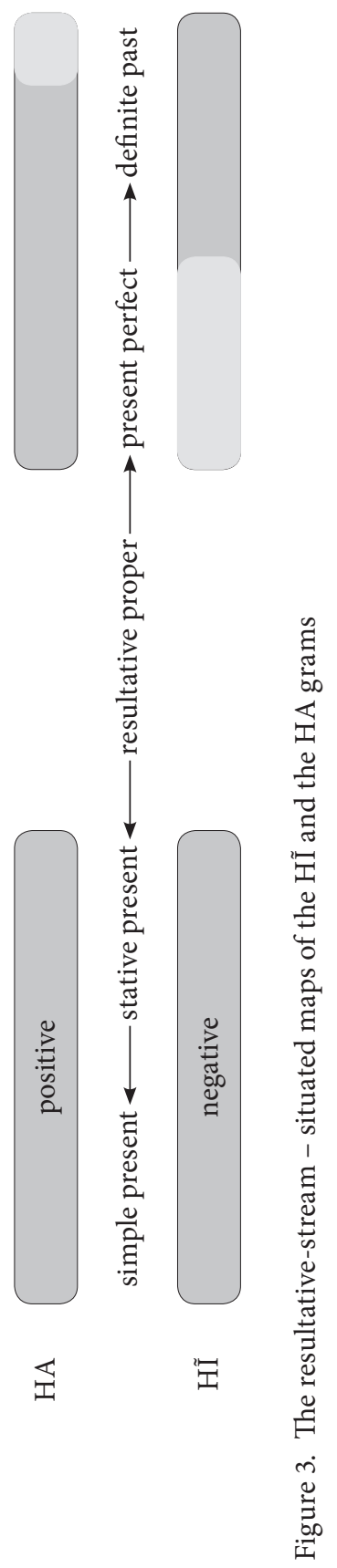

the simultaneous path. To be exact, verbs which in their negative forms exhibit stative or non-stative present senses and follow the simultaneous path, are interpreted dynamically as actional perfects or pasts in affirmative constructions. As a result, in the module of the Tjwao verbal system analyzed in this section (i.e. the resultative-stream module), we define the HII gram as a preceding and escaping vector, while the HA gram is defined as a following and chasing vector (see Figure 3 below).

The respective topologies of the HĨ and HA constructions and their differences in advancement on the resultative stream suggest that the HĨ gram is older than the HA gram. This, in turn, explains the similarities and dissimilarities of the two grams. The older HĨ gram has travelled the resultative path for a larger extent of time, reaching further zones of the stream (narrative remote past) and abandoning the initial ones (resultative proper and most areas of the present perfect). In contrast, the younger HA gram has existed for a shorter period of time and therefore advanced on the stream to a lesser extent. It is compatible with initial senses available on the path (values of a present perfect), failing to reach to its ultimate sections (narrative remote past) (see Figure 3 below).

Consequently, both the semantic overlap of the HĨ and the HA gram and their range of differences determined in this study may be viewed as natural. The similarities stem from the identical grammaticalization path travelled by the two constructions. The dissimilarities derive from a distinct advancement on the path - itself conditioned by the different chronology of the two forms.

The results of our study indicate that Tjwao conforms to the constructional entanglement exhibited in those Khoe languages that include in their verbal repertories cognates of both the HĨ and the HA construction. As mentioned in Section 1, in these types of languages, exemplified by Khwe (KilianHatz 2006) and Kora (Du Plessis 2017), the cognates of HĨ usually function as general or remote pasts, while the cognates of HA convey senses of present perfects or completives, additionally exhibiting 
a present stative usage (Kilian-Hatz 2006: 102-104, 106; Du Plessis 2017: 140, 143). ${ }^{16}$ Thus, the former (i.e. HĨ-type grams) tend to be grammatically more advanced than the latter (i.e. HA-type grams). Tjwao complies with this tendency, since, as demonstrated above, the HĨ gram occupies further sections of the resultative stream than the HA gram.

\section{Conclusion}

The present paper offered a cognitive grammaticalization-based analysis of the TAM semantics of the HI and HA grams in Tjwao in terms of dynamic maps located on a shared stream. First, we showed that, even though similar, the ranges of polysemy of the two forms differ. The grams share the values of experiential present perfect, various types of definite past, stative present, and non-stative present. They differ, however, in the senses of narrative remote past and pluperfect (limited to or typical of $\mathrm{HI}$ ), as well as the senses of inclusive and resultative present perfect (compatible only with HA). Moreover, the two grams are used as presents (stative or non-stative) in distinct polarity contexts: HA appears in the affirmative, while HĨ is found in the negative. Second, we demonstrated that the meanings of the two grams can be grasped in their totality - preserving both their semantic diversity and coherence by making use of two sub-paths of the resultative path, i.e. the anterior and the simultaneous path. Third, we argued that the two constructions may be located on the same stream, with the HĨ gram being more advanced than the HA gram. This, in turn, suggested that the HĨ gram is chronologically older than the HA gram. Overall, Tjwao was proven to conform to the tendency exhibited by other Khoe languages where the cognates of the HĨ gram tend to be more grammatically advanced than the cognates of the HA gram.

Although our study provided a more nuanced analysis of the HI and HA grams in Tjwao, it did not clarify all issues related to these two verbal constructions. First, our research and, thus, the maps and the structure of the stream are purely qualitative. We are aware of the fact that the senses present in the semantic potential of the analyzed constructions are not equally relevant - some are prototypical (e.g. common and productive), others are not. Second, although the HĨ and HA grams share parts of their semantic potential, they need not be fully interchangeable. Rather, their selection (or preference) may be conditioned by syntactic, discourse-pragmatic, stylistic, or genre related factors. As a result, a quantitative study (e.g. related to the frequencies of senses as attested in discourse) and a multi-factorial analysis expanding beyond purely semantic TAM considerations are necessary to understand more accurately the differences and the entanglement of the two grams. Such research will be undertaken by the authors of this paper in the near future.

16 However, this is not universal. In some languages, e.g. in Ts' ixa, the cognates of HA exhibit a fully advanced profile, functioning as a generic and remote past (Fehn 2016: 145, 147-149). Concerning the cognates of the two Tjwao grams in Khoekhoe, consult Hagman (1977), Vossen (1997), Heine (1999), Kilian-Hatz (2008), Haacke (2013a, b, 2014), Rapold (2014), and Du Plessis (2017). 


\section{Abbreviations}

ADV - adverbial (morpheme); ANT - anterior; C - common gender; COP - copula; DEM demonstrative; DU - dual; F - feminine; HA - the morpheme / gram - ha; HĨ - the morpheme/ gram -hĩ IPFV - imperfective; J - juncture; LOC - locative; M - masculine; NEG - negator/ negation; OBL - oblique; PL - plural; PN - proper noun; POSS - possessive; Q - question marker; REF - referential; SG - singular; TAM - tense/aspect/mood.

\section{References}

Andrason. A. 2011. The Biblical Hebrew Wayyiqtol - a dynamic definition. - Journal of Hebrew Scriptures 11.7: 1-50.

Andrason. A. 2013. El sistema verbal hebreo en su contexto semítico: una visión dinámica. Estella.

Andrason A. 2014. From resultatives to present tenses - Simultaneous path of resultative constructions. - Italian Journal of Linguistics 26.1: 1-58.

Andrason A. 2015. Toward the ocean of the Biblical Hebrew verbal system. - Folia Orientalia 52: $15-36$.

Andrason A. 2016a. A complex system of complex predicates: Tense, taxis, aspect and mood in Basse Mandinka from a grammaticalization and cognitive perspective. [PhD Diss., University of Stellenbosch].

Andrason A. 2016b. From vectors to waves and streams: An alternative approach to semantic maps. - Stellenbosch Papers in Linguistics 45: 1-29.

Andrason A., Karani M. 2017. The perfective form in Arusa - A cognitive-grammaticalization model. - Asian and African Studies 26.1: 69-101.

Andrason A., Locatell C. 2016. The perfect wave. - Biblical and Ancient Greek Linguistics 5: 7-121.

Bybee J. 2010. Language, usage and cognition. Cambridge.

Bybee J., Perkins R., Pagliuca W. 1994. The evolution of grammar. Chicago.

Croft W. 2003. Typology and universals. Cambridge.

Dahl Ö. 1985. Tense and aspect systems. Oxford.

Dahl Ö. (ed.). 2000. Tense and aspect in the languages of Europe. Berlin.

Dornan S.S. 1917. The Tati Bushmen (Masarwas) and Their Language. - Journal of the Royal Anthropological Institute 47.1: 37-112.

Drinka B. 1998. The evolution of grammar: Evidence from Indo-European perfects. Schmid M., Austin J., Stein D. (eds.). Historical linguistics 1997. Amsterdam: 117-133.

Du Plessis M. 2017. Kora: A lost Khoisan language of the early Cape and the Gariep. Pretoria.

Elderkin E.D. 1986. Kxoe tone and Kxoe 'jonctures'. - Vossen R., Keuthmann K. (eds.). Contemporary studies on Khoisan. Hamburg: 225-235.

Fehn A.-M. 2016. A grammar of Ts'ixa (Kalahari Khoe). [PhD Diss., University of Cologne].

Fehn A.-M., Phiri A. 2017. Nominal marking in Northern Tshwa (Kalahari Khoe). - Stellenbosch Papers in Linguistics 48: 105-122.

Georgakopoulos T., Polis S. 2018. The semantic map model: State of the art and future avenues for linguistic research. - Language and Linguistic Compass 12.2: 1-33.

Güldemann T. 2014. 'Khoisan' linguistic classification today. - Güldemann T., Fehn A.-M. (eds.). Beyond 'Khoisan'. Historical relations in the Kalahari basin. Amsterdam: 1-40.

Güldemann T., Fehn A.-M. 2014. A Kwadi perspective on Khoe verb-juncture constructions. [Paper presented at the $5^{\text {th }}$ International Symposium on Khoisan Languages and Linguistics, Riezlern. July 14-16, 2014]. 
Güldemann T., Fehn A.-M. 2017. The Kalahari basin area as a 'Sprachbund' before the Bantu expansion. - Hickey R. (ed.). The Cambridge handbook of areal linguistics. Cambridge: 500-526.

Güldemann T., Vossen R. 2000. Khoisan. - Heine B., Nurse D. (eds.). African languages: An introduction. Cambridge: 99-122.

Haacke W. 2013a. Syntax [Namibian Khoekhoe]. - Vossen R. (ed.). The Khoesan languages. Milton Park: 325-340.

Haacke W. 2013b. Syntax [!Gora]. - Vossen R. (ed.). The Khoesan languages. Milton Park: 340-347.

Haacke W. 2014. Verb serialization in Northern dialects of Khoekhoegowab. Convergence or divergence? - Güldemann T., Fehn A.-M. (eds.). Beyond 'Khoisan'. Historical relations in the Kalahari basin. Amsterdam: 123-149.

Hachipola S.J. 1998. A survey of the minority languages of Zimbabwe. Harare.

Hagman R. 1977. Nama Hottentot grammar. Bloomington.

Haspelmath M. 2003. The geometry of grammatical meaning. Semantic maps and cross-linguistic comparison. - Thomasello M. (ed.). The new psychology of language. Mahwah: 211-242.

Heine B. 1986. Bemerkungen zur Entwicklung der Verbaljunkturen im Kxoe und anderen Zentralkhoisan-Sprachen. - Vossen R., Keuthmann K. (eds.). Contemporary studies on Khoisan. Hamburg: 9-21.

Heine B. 1997. Cognitive foundations of grammar. Oxford.

Heine B. 1999. The IIAni: Grammatical notes and texts. Cologne.

Heine B., Claudi U., Hünnemeyer F. 1991. Grammaticalization. A conceptual framework. Chicago.

Heine B., Kuteva T. 2006. The changing languages of Europe. Oxford.

Janda L. 2015. Cognitive Linguistics in the year 2015. - Cognitive Semantics 1: 131-154.

Kilian-Hatz C. 2006. Serial verb constructions in Khwe (Central Khoisan). - Aikhenvald A., Dixon R.M.W. (eds.). Serial verb constructions: A cross-linguistic typology. Oxford: 108-123.

Kilian-Hatz C. 2008. A grammar of Modern Khwe (Central Khoisan). Cologne.

Köhler O. 1981. Les langues Khoisan, section 1: Présentation d'ensemble. - Perrot J. (ed.). Les langues dans le monde ancien et modern. Les langues de l'Afrique subsaharienne. Paris: 455-482.

Köhler O. 1989. Die Welt der Kxoé-Buschleute im südlichen Afrika: Eine Selbstdarstellung in ihrer eigenen Sprache. [vol. 1: Die Kxoé-Buschleute und ihre ethnische Umgebung]. Berlin.

Malchukov A. 2004. Towards a semantic typology of adversative and contrast marking. Journal of Semantics 21: 177-198.

Maslov J. 1988. Resultative, perfect and aspect. - Nedjalkov V. (ed.). Typology of resultative constructions. Amsterdam: 63-85.

Narrog H., Van der Auwera J. 2011. Grammaticalization and semantic maps. - Narrog H., Heine B. (eds.). The Oxford handbook of grammaticalization. Oxford: 318-327.

Nedjalkov V. 2001. Resultative constructions. - Haspelmath M. et al. (eds.). Language typology and language universals: An international handbook. [vol. 2]. Berlin: 928-940.

Nedjalkov V., Jaxontov S. 1988. The typology of resultative constructions. - Nedjalkov V. (ed.). Typology of resultative constructions. Amsterdam: 3-63.

Phiri A. 2015. Tshwao phoneme inventory: A descriptive account. [MA Diss. University of Zimbabwe].

Phiri A., Wills J. 2016. Ti kwa Tjwao k’ui. [Unpublished manuscript].

Rapold C. 2014. Areal and inherited aspects of compound verbs in Khoekhoe. - Güldemann T., Fehn A.-M. (eds.). Beyond 'Khoisan'. Historical relations in the Kalahari basin. Amsterdam: 153-177. 
Rosch E. 1975. Cognitive representations of semantic categories. - Journal of Experimental Psychology: General 104: 192-233.

Rosch E., Mervis C.B. 1975. Family resemblances: Studies in the internal structure of categories. - Cognitive Psychology 7: 573-605.

Squartini M., Bertinetto P.-M. 2000. The simple and compound past in Romance languages. Dahl Ö. (ed.). Tense and aspect in the languages of Europe. Berlin: 385-402.

Taylor J.R. 2003. Linguistic categorization. Oxford.

Vossen R. 1997. Die Khoe-Sprachen: Ein Beitrag zur Erforschung der Sprachgeschichte Afrikas. Cologne.

Vossen R. 1998. Historical classification of Khoe (Central Khoisan) languages of Southern Africa. - African Studies 57: 93-106.

Vossen R. 2010. The verbal linker in Central Khoisan (Khoe) in the context of deverbal derivation. - Journal of Asian and African Studies 80: 47-60. 